\title{
Role of $\beta 4$ integrin phosphorylation in human invasive squamous cell carcinoma: regulation of hemidesmosome stability modulates cell migration
}

\author{
Trinayan Kashyap¹, Emily Germain ${ }^{1}$, Michael Roche², Stephen Lyle ${ }^{2}$ and Isaac Rabinovitz
}

Hemidesmosomes (HDs) are multiprotein structures that anchor epithelia to the basement membrane. During squamous cell carcinoma (SCC) invasion, there is a reduction in the number of HDs, which may facilitate dissemination. Mechanisms of HD disassembly are incompletely understood. Previous work has shown that epidermal growth factor (EGF)-induced phosphorylation of the $\beta 4$ integrin on three of its serines, $\mathrm{S}_{1356} \mathrm{~S}_{1360} \mathrm{~S}_{1364}$, can induce HD disassembly in normal cells. Here, we examine the role of $\beta 4$ integrin serine phosphorylation in SCC. We have found that around $60 \%$ of invasive cutaneous SCC show increased $\beta 4$ phosphorylation on $\mathrm{S}_{1356}$ when compared with carcinoma in situ or normal tissue. To assess the mechanisms by which SCC increases $\beta 4$ phosphorylation, we performed in vitro analyses. Compared with keratinocytes, SCC cells showed increased levels of $S_{1356}$ phosphorylation in the absence of EGF, correlating with reduced HD-like structures. In addition, phospho- $\mathrm{S}_{1356}$ signal was largely segregated from other HD components. Epidermal growth factor receptor and PKC inhibitors inhibited basal levels of $\mathrm{S}_{1356}$ phosphorylation in SCC, suggesting that cells use intrinsic mechanisms to activate the EGF signaling pathway to induce $\beta 4$ phosphorylation. Moreover, these inhibitors stabilized HD-like structures in SCC cells and reduced their migratory ability. Mutation of $\mathrm{S}_{1356} \mathrm{~S}_{1360} \mathrm{~S}_{1364}$ in SCC cells to non-phosphorylatable alanines stabilized HD-like structures and substantially reduced migration, while mutation into phosphorylation mimicking aspartate reduced HD-like structures but had no effect on migration, suggesting that serine phosphorylation function is releasing anchorage rather than promoting migration. Altogether these results suggest that $\beta 4$ serine phosphorylation may have an important role during SCC invasion by destabilizing HDs and facilitating migration.

Laboratory Investigation (2011) 91, 1414-1426; doi:10.1038/labinvest.2011.104; published online 18 July 2011

KEYWORDS: cell migration; hemidesmosome; integrins; invasion; phosphorylation

Squamous cell carcinomas (SCCs) are highly invasive tumors capable of metastasis. ${ }^{1-3}$ Stratified squamous epithelia, where most of the SCCs originate from, are strongly attached to the basal lamina through hemidesmosomes (HDs), multiprotein structures that provide stability. ${ }^{4,5}$ During wound healing or SCC invasion, there is an increase in HD disassembly. ${ }^{6,7}$ In some SCC types, HD disassembly has been shown to correlate with metastatic potential. ${ }^{7}$ For this reason, there is a considerable interest to understand the mechanisms of HD disassembly.

The mechanisms of HD disassembly are not completely understood. Studies suggest that phosphorylation of the $\alpha 6 \beta 4$ integrin, has an important role in HD disassembly. ${ }^{8-12}$ The $\alpha 6 \beta 4$ integrin is the main organizer of HDs. ${ }^{13} \alpha 6 \beta 4$ connects to laminin on the basal lamina and facilitates the assembly of other HD components, including plectin and BPAG1 (bullous pemphigoid antigen 1), which link $\alpha 6 \beta 4$ to cytokeratins. $^{4,5,13}$

The chain of events that leads to HD disassembly in SCC is not well understood. Growth factors might trigger the initial events. Supporting this idea, epidermal growth factor (EGF) and macrophage-stimulating protein have been shown to induce HD disassembly in vitro. ${ }^{14-16}$ These factors activate signaling pathways that result in $\beta 4$ phosphorylation. EGF induces phosphorylation of $\beta 4$ on serine and tyrosine residues, several of which have been identified and shown to be involved in HD disassembly. ${ }^{8-11,14}$ Around $95 \%$ of $\beta 4$ phosphorylation induced by EGF occurs on serine, ${ }^{8,15}$ mostly

${ }^{1}$ Department of Pathology, BIDMC/Harvard Medical School, Boston, MA, USA and ${ }^{2}$ Department of Pathology, UMass Medical School, Worcester, MA, USA Correspondence: Dr I Rabinovitz, MD, PhD, Department of Pathology, Beth Israel Deaconess Medical Center, 330 Brookline Avenue, Boston, MA 02215, USA. E-mail: irabinov@bidmc.harvard.edu 
on four sites, $S_{1356}, S_{1360}, S_{1364}$, and $S_{1424 .}{ }^{8,9,11}$ In normal cells, substitution of these serines with alanine impedes phosphorylation and in a cooperative manner can inhibit EGF-induced HD disassembly. ${ }^{8,9,11}$ The mechanism by which $\beta 4$ serine phosphorylation induces disruption of HDs is unclear, although evidence suggests that $\mathrm{S}_{1356} \mathrm{~S}_{1360} \mathrm{~S}_{1364}$ phosphorylation controls $\alpha 6 \beta 4 /$ plectin interaction. ${ }^{11}$

One possible scenario to explain reduced HDs in SCC is that $\beta 4$ phosphorylation may be altered, changing the balance toward disassembly. There is little information about $\beta 4$ phosphorylation in SCC or its impact on HDs in cell migration. In this study, we analyzed $\beta 4$ phosphorylation in primary SCC as well as in SCC cells in vitro. SCC frequently shows alterations in EGF receptor (EGFR) signaling, ${ }^{17,18}$ so we analyzed phospho- $S_{1356}$, a $\beta 4$ residue whose phosphorylation is EGF dependent. We found that $S_{1356}$ phosphorylation in primary SCC correlates with invasiveness. In vitro analysis showed that SCC cells have intrinsic mechanisms to increase the basal level of $\beta 4$ phosphorylation in the absence of EGF, reducing HD-like structures stability. Interestingly, SCC cells still use EGFR and PKC in the absence of exogenous EGF. Gefitinib, an EGFR kinase inhibitor, increased HD-like structures stability by reducing $\beta 4$ phosphorylation, affecting cell migration as well. Mutation of $\beta 4$ $\mathrm{S}_{1356} \mathrm{~S}_{1360} \mathrm{~S}_{1364}$ into alanines stabilized HD-like structures and hindered SCC migration. Our results suggest that $\beta 4$ phosphorylation has an important role in SCC progression by altering HD stability and the ability of cells to migrate. Targeting HD stability may be a method to reduce the ability of SCC to disseminate.

\section{MATERIALS AND METHODS Cells and Reagents}

SCC cell lines: A431 cells were obtained from ATCC; Colo-16 cells were obtained from Dr N Hail (University of Colorado, Denver, CO, USA); SCC- 25 cells were provided by Dr AM Mercurio (UMass Med, Worcester, MA, USA). HaCaT keratinocytes were obtained from Dr S La Flamme (Albany Medical College, Albany, NY, USA). All cells were maintained in DMEM with $10 \%$ fetal calf serum, except SCC-25 that was maintained in a 1:1 mixture of DMEM and Ham's F12 medium supplemented with $400 \mathrm{ng} / \mathrm{ml}$ hydrocortisone and $10 \%$ fetal bovine serum. Antibodies: 3E1 ( $\beta 4$, Chemicon); GoH3 ( $\alpha 6$, Chemicon); rabbit anti- $\beta 4 ;{ }^{15}$ anti-BPAG1; ${ }^{19}$ antiplectin (Santa Cruz Biotechnology); affinity-purified phospho-specific rabbit polyclonal $\mathrm{Ab}$ (anti-phospho- $\mathrm{S}_{1356} \mathrm{Ab}$ ) raised against $\beta 4$ peptide DDVLR(pS)PSGSQ (custom-made, QBC, Hopkinton, MA, USA).

\section{Plasmids}

B4shRNA-A431cells

pLKO.1 $\beta 4$-shRNA TRCN0000057768 (Open Biosystems) against an untranslated region of $\beta 4$ was used to inhibit $\beta 4$ endogenous expression in A431. pLKO.1GFP-shRNA was used as control. Cells were puromycin selected.

\section{B4-PCLXSN and triple mutants}

$\beta 4$ Integrin cDNA fused to a C-terminus myc tag was inserted in PCLXSN retroviral vector (Imgenex). A triple mutation ser $\rightarrow$ ala or ser $\rightarrow$ asp on $\mathrm{S}_{1356} \mathrm{~S}_{1360} \mathrm{~S}_{1364}$ was introduced into $\beta 4$-myc using standard techniques. ${ }^{9}$ Retroviral particles were used to infect $\beta 4$ shRNA-A431cells. As control, we used the empty vector. Cells were selected using G418 and $\beta 4$ negative cells were eliminated by FACS sorting.

\section{Indirect Immunofluorescence}

Cells were stained as described previously. ${ }^{15,20}$ Briefly, cells grown on coverslips were extracted or not, with detergent buffer containing $0.5 \%$ Triton-X-100, $100 \mathrm{mM} \mathrm{KCl}, 200 \mathrm{mM}$ sucrose, $10 \mathrm{mM}$ EGTA, $2 \mathrm{mM} \mathrm{MgCl}$, and $10 \mathrm{mM}$ PIPES at $\mathrm{pH} 6.8$ for $1 \mathrm{~min}$, then fixed using paraformaldehyde or methanol. Cells were rinsed, blocked and stained with indicated $\mathrm{Abs}$ and $\mathrm{Cy} 2 / \mathrm{Cy} 3$-conjugated secondaries. Slides were analyzed using fluorescence microscopy. Analysis of HD-like structures: collected images were background-subtracted, thresholded and fluorescence integrated density per cell was calculated using ImageJ software (NIH).

\section{In Vitro Wound Healing Assay}

Cells grown to confluency were scratched with a yellow tip, and new medium containing inhibitors or not, was added. Image records were collected at time 0 . Wounded plates were incubated for 8-24h. Images were collected and percentage of wound closure was determined by digital analysis.

\section{Human Tissue Samples}

Tissue sections were obtained from the Cancer Center Tissue and Tumor Bank of UMASSMed with IRB approval. Formalin-fixed paraffin-embedded (FFPE) sections were stained with indicated antibodies using standard immunoperoxidase technique. Frozen sections were fixed in methanol, rinsed, blocked, and stained with indicated antibodies followed by cy2/cy3-conjugated secondaries. Slides were analyzed by fluorescence microscopy. Staining intensities were scored from 0 (absent) to 4 (very strong) by two observers (SL and IR). Colocalization analysis in frozen sections was performed using Image $(\mathrm{NIH})$ and Colocalization Threshold plugin ${ }^{21}$ (http://www.uhnresearch.ca/facilities/wcif/software/Plugins/ colocalisation_threshold.html). Statistical analysis was performed using $t$-test.

\section{RESULTS \\ Phosphorylation of the $\beta 4$ Integrin in Primary Human SCC Correlates With Invasion}

EGF signaling is frequently altered in SCC. ${ }^{17,18}$ We have previously identified $S_{1356}$ as one of the main phosphorylation sites on the $\beta 4$ integrin that is phosphorylated upon EGF stimulation in a PKC-dependent manner using peptide mapping analysis, results that have been confirmed by other groups. ${ }^{8,11}$ We and others have also shown that $S_{1356}$ phosphorylation contributes importantly in HD disassembly. ${ }^{8,11}$ 

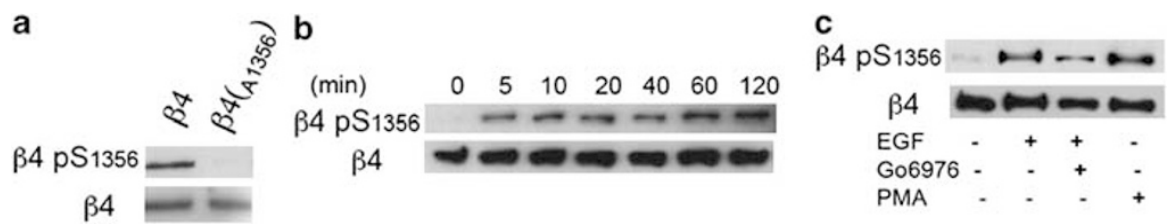

Figure 1 Regulation of $\beta 4$ phosphorylation (phospho- $\mathrm{S}_{1356}$ ) by EGF in HaCaT keratinocytes. (a) Anti-phospho- $\mathrm{S}_{1356}$ Ab specificity. Lysates obtained from EGF-stimulated Cos-7 cells transfected with wt $\beta 4$ or mutant $\beta 4 \mathrm{~A}_{1356}$ were probed with Abs against $\beta 4$ and phospho- $\mathrm{S}_{1356}$. (b) Time course of $\mathrm{S}_{1356}$ phosphorylation in $\mathrm{HaCaT}$ keratinocytes. Cells were serum-starved and EGF-stimulated ( $50 \mathrm{ng} / \mathrm{ml})$ for different times, and analyzed by western blotting using phospho- $\mathrm{S}_{1356}$ and $\beta 4$ Abs. (c) $\mathrm{S}_{1356}$ phosphorylation is PKC dependent. HaCaT keratinocytes were EGF-stimulated in the presence or absence of conventional PKC inhibitor Go6976, or with PMA, then analyzed by western blotting using phospho- $\mathrm{S}_{1356}$ and $\beta 4$ Abs.

Therefore, we generated a phospho-specific $\mathrm{Ab}$ against phospho- $S_{1356}$. To assess $\mathrm{Ab}$ specificity, we mutated $\beta 4$ $S_{1356} \rightarrow A_{1356}$ to prevent $A b$ recognition of phospho- $S_{1356}$. As shown in Figure 1a, mutation of the residue eliminated the phospho- $\mathrm{S}_{1356} \mathrm{Ab}$ signal, confirming specificity. To confirm that the $\mathrm{Ab}$ acts in accordance to previous studies, we evaluated the kinetics of $S_{1356}$ phosphorylation in $\mathrm{HaCaT}$ keratinocytes during EGF stimulation using phospho- $\mathrm{S}_{1356}$ $\mathrm{Ab}$ and western analysis. As shown in Figure 1b, there is little phosphorylation in non-stimulated cells, rapidly increasing to high levels after $5 \mathrm{~min}$ and maintaining levels for $2 \mathrm{~h}$. Previous work suggests that phosphorylation of some of the serines in $\mathrm{S}_{1356} \mathrm{~S}_{1360} \mathrm{~S}_{1364}$ serine cluster are PKC dependent. ${ }^{8,11}$ Therefore, we analyzed the effects of PKC stimulators and inhibitors on $S_{1356}$ phosphorylation. As shown in Figure 1c, EGFdependent phosphorylation can be inhibited with conventional PKC inhibitor Go6976. Furthermore, PKC stimulator PMA induces $S_{1356}$ phosphorylation, suggesting PKC dependence. Altogether these results indicate that the $\mathrm{Ab}$ is specific and performs as expected in accordance to previous work.

To assess the prevalence of $\beta 4$ phosphorylation in human SCC, we analyzed $S_{1356}$ phosphorylation in normal skin and primary SCC. Archival FFPE or frozen sections were analyzed using immunohistochemistry (IHC) or immunofluorescence (IF) analysis, respectively.

FFPE sections from 20 cutaneous SCC were stained for phospho- $S_{1356}$. Tissues were divided into five categories: normal skin $(n=4)$; carcinoma in situ $(n=7)$; well $(n=4)$, moderately $(n=5)$, or poorly differentiated $(n=4)$ invasive carcinoma. Staining intensities were scored $0=$ absent to $4=$ very strong. In normal skin, $\beta 4$ was expressed in basal cells (Figure 2a) as previously described. ${ }^{22}$ Phospho- $S_{1356}$ stain was mostly negative (Figure $2 \mathrm{~b}$ ). In carcinoma in situ, $\beta 4$ was highly expressed (Figure $2 \mathrm{c}$ ), sometimes observed in suprabasal levels, and there was little $\beta 4$ phosphorylation (Figure $2 \mathrm{~d}$ ). In invasive carcinomas, $\beta 4$ expression remained high, sometimes extending beyond the basal layer (Figures $2 \mathrm{e}$ and g). In contrast to normal skin and carcinoma in situ, invasive SCC showed increased phospho- $\mathrm{S}_{1356}$ (Figures $2 \mathrm{f}$ and $h$ ). The signal was specific because it was eliminated by incubating the primary antibody in the presence of competing phospho- $S_{1356}$ peptide, or by treating the tissue with alkaline phosphatase before adding the primary antibody (results not shown). Around $60 \%$ of the invasive tumors showed high levels of phospho- $\mathrm{S}_{1356}$ with IHC scores higher than normal skin (Figure 2i). However, we found no difference between invasive carcinomas according to their degree of differentiation. $\beta 4$ phosphorylation could be found along the tumor/stroma interface (Figure $2 \mathrm{~h}$ ), or extending deeply into the tumor (Figure $2 \mathrm{f}$ ) usually codistributing with $\beta 4$. The increased phosphorylation of the $\beta 4$ integrin in invasive SCC suggests that phosphorylation may have a role during this tumor progression phase.

\section{Distribution Pattern of $\beta 4$ Phosphorylation in Relation to Total $\beta 4$, Basement Membrane and Other HD Components in Human SCC}

To assess more closely the relationship between the $\beta 4$ phosphorylation signals and total $\beta 4$, other HD components or the basement membrane in human SCC, we analyzed nine cutaneous SCC (all invasive, three well and six moderately differentiated) and two normal skin frozen sections using double IF. Consistent with IHC results, normal skin showed high levels of $\beta 4$ expression and little $\beta 4$ phosphorylation (Figures $3 \mathrm{a}-\mathrm{c}$ ). About $60 \%$ of the invasive SCC sections showed moderate-to-high levels of $\beta 4$ phosphorylation (Figures $2 \mathrm{i}$ and $3 \mathrm{e}, \mathrm{h}$, and $\mathrm{k}$ ). $\beta 4$ phosphorylation varied within regions, frequently showing gaps in relation to the band-like signal of $\beta 4$ (arrows Figures $3 \mathrm{e}, \mathrm{f}, \mathrm{h}$, and i), suggesting that phosphorylation is regionally modulated. Phosphorylation was stronger at the tumor/stroma interface sometimes extending more deeply (Figures $3 \mathrm{e}$ and $\mathrm{h}$ ), similar to FFPE sections.

To assess whether the discontinuous pattern of $\beta 4$ phosphorylation corresponds to basement membrane disruptions along the tumor/stroma interface, we analyzed colocalization of phospho- $\mathrm{S}_{1356}$ and Laminin-332. As shown in Figures 3g-i, Laminin-332 was continuous and did not correlate with the patchy pattern of $\beta 4$ phosphorylation, suggesting that $\beta 4$ phosphorylation is unrelated to the basement membrane. To assess if $\beta 4$ phosphorylation affects the distribution of other HD components, we evaluated colocalization of BPAG1 and phospho- $S_{1356}$. The patchy pattern of both BPAG1 and $\beta 4$ phosphorylation frequently excluded each other (Figures $3 \mathrm{j}-1$ ), suggesting that $\beta 4$ phosphorylation may affect the distribution of this HD component. 

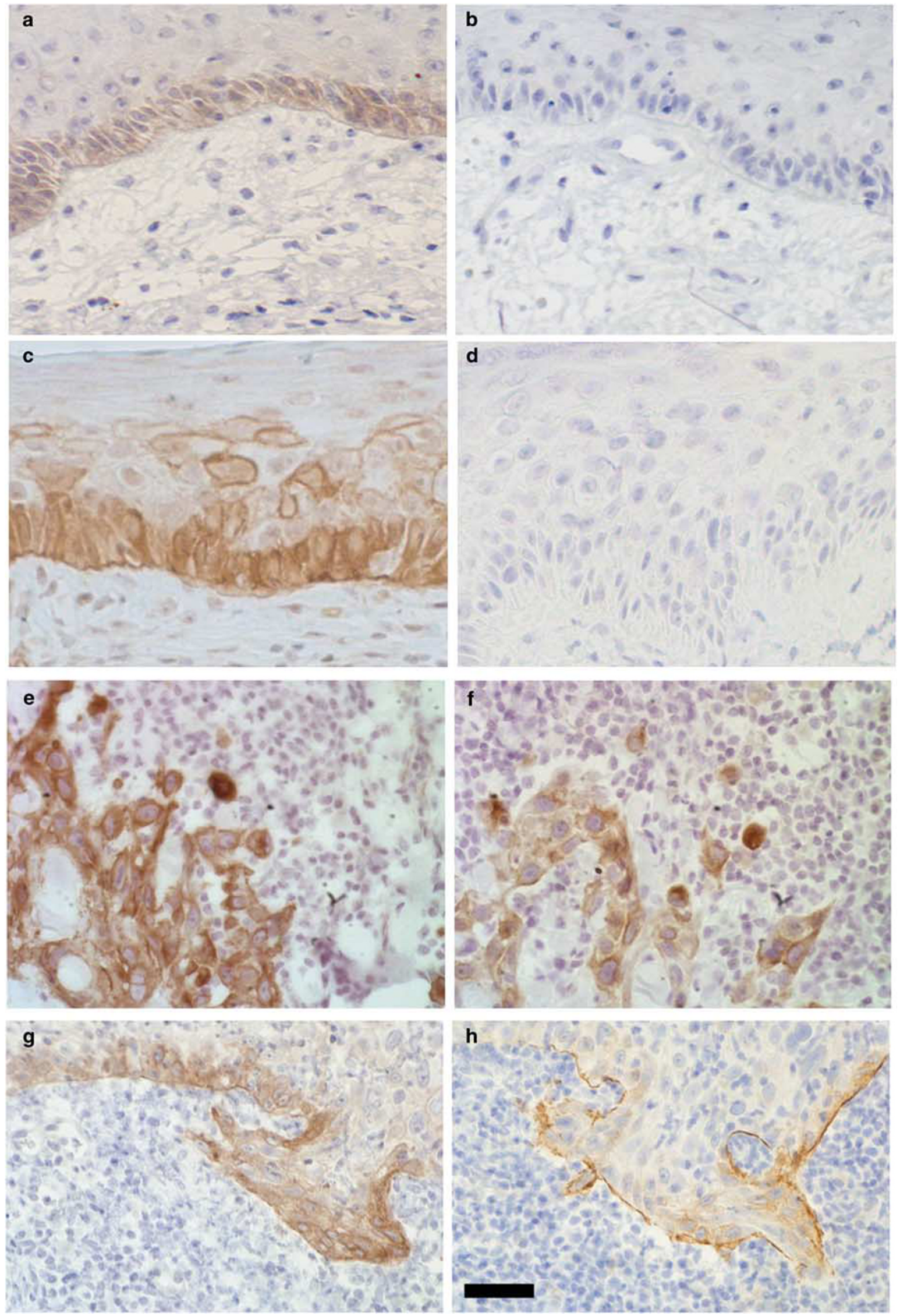

Figure 2 For caption see next page. 


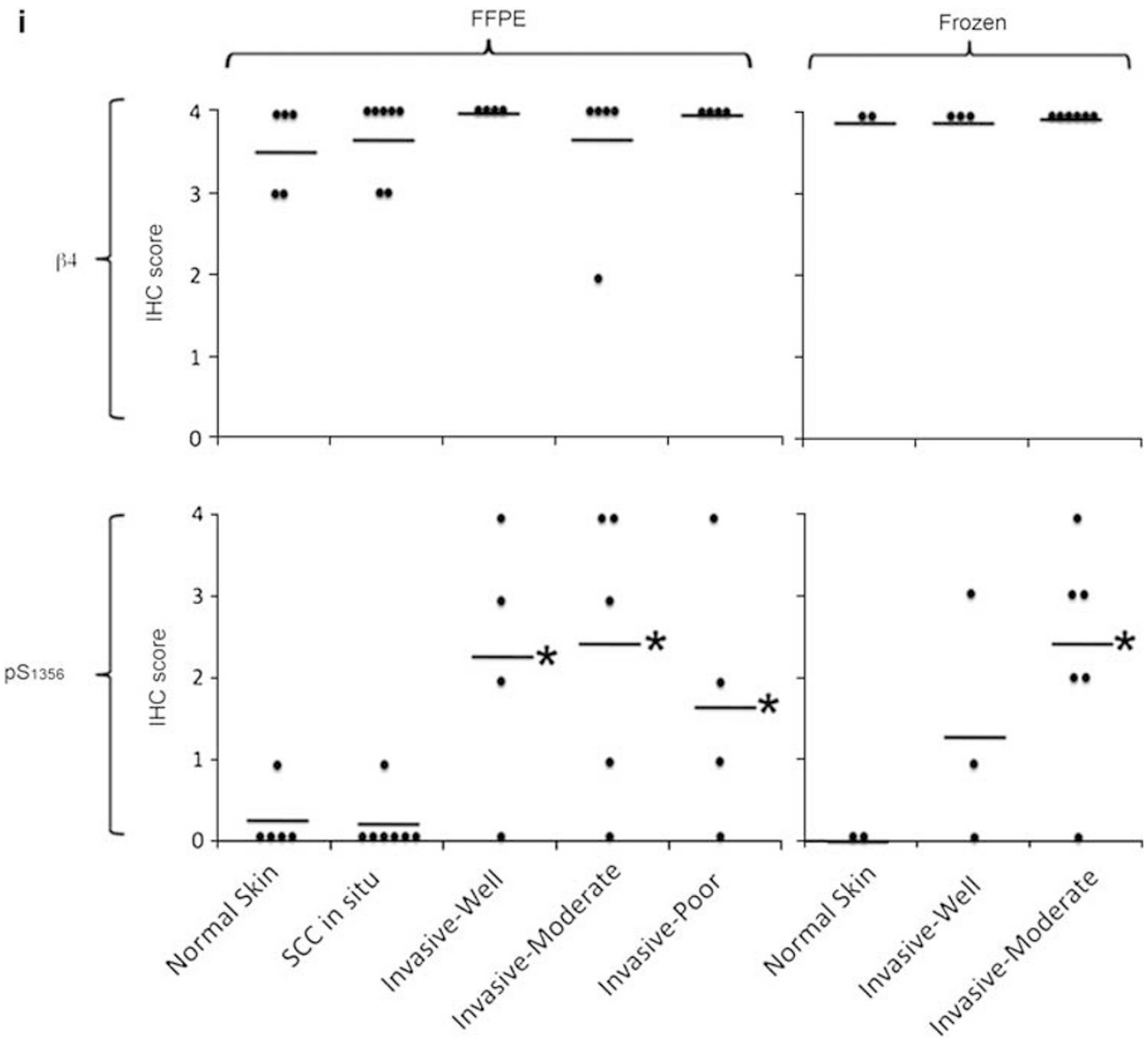

Figure 2 Phosphorylation of the $\beta 4$ integrin is increased in human SCC. (a-h) FFPE sections stained with $\beta 4$ integrin (a, c, e, g) and phospho- $\mathrm{S}_{1356}$ $(\mathbf{b}, \mathbf{d}, \mathbf{f}, \mathbf{h})$. Abs were revealed by IHC in normal skin $(\mathbf{a}, \mathbf{b})$, carcinoma in situ $(\mathbf{c}, \mathbf{d})$, and well differentiated (e, f) or poorly differentiated $(\mathbf{g}, \mathbf{h})$ invasive cutaneous SCC. Bar $=100 \mu \mathrm{m}$. (i) Frequency plots of predominant IHC score for $\beta 4$ and phospho-S $\mathrm{S}_{1356}$ in tissue sections. FFPE (left panels) or frozen sections (right panels) were scored based on the observed staining intensity of indicated Abs, using a scale of $0-4$. Each symbol represents a separate section and the horizontal line represents the mean score for each category. ${ }^{*} P<0.05$.

Increased Basal Level of $S_{1356}$ Phosphorylation in SCC Cells Is Associated With Reduced HD-Like Structure Stability

The higher levels of phosphorylation observed in invasive primary SCC and previous observations that HDs are reduced in $\mathrm{SCC}^{7}$ prompted us to assess in vitro for possible mechanisms explaining these observations. Reduced HDs in SCC may be related to alterations in $\beta 4$ phosphorylation. We, therefore, analyzed the levels and distribution of $\mathrm{S}_{1356}$ phosphorylation in three SCC cell lines: A431, ${ }^{23}$ SCC- $25^{24}$ and Colo- $16^{25}$ in relation to $\mathrm{HaCaT}$ keratinocytes, which are immortalized keratinocytes capable of differentiation in organotypic cultures and formation of HD-like structures in vitro. ${ }^{26}$ Western analysis showed that, in comparison to HaCaT keratinocytes, all SCC cells had elevated basal levels of phospho- $\mathrm{S}_{1356}$ in the absence of EGF (Figures $4 \mathrm{a}$ and b), suggesting intrinsic mechanisms to increase phosphorylation. We then compared the phospho- $S_{1356}$ distribution between $\mathrm{HaCaT}$ keratinocytes and SCC cells using IF (Figures $4 \mathrm{c}$ and e). The cells were dual immunostained with $\beta 4$ and phospho$\mathrm{S}_{1356}$ Abs. HaCaT keratinocytes showed characteristic HDlike structures stained with the $\beta 4 \mathrm{Ab}$ that largely survived extraction with detergent buffer before fixation (Figure 4c; non-Ex: non-extracted; Ex: extracted). The resistance to detergent buffer is mostly conferred by the connection of the $\beta 4$ integrin with the cytokeratins through plectin and BPAG1. ${ }^{27,28}$ As expected, most of the $\beta 4$ that remains after detergent extraction in HD-like structures colocalizes with plectin (Figure 4d). Using quantitative IF, we determined that about $60 \%$ of HaCaT $\beta 4$ is resistant to detergent (Figure $4 \mathrm{e}$ ). The phospho- $\mathrm{S}_{1356}$ signal was low in $\mathrm{HaCaT}$ keratinocytes (Figure 4c). In contrast, SCC cells showed a higher phospho$\mathrm{S}_{1356}$ signal in all three SCC cell lines (Figure 4c), which colocalized with $\beta 4$ in HD-like structures and retraction fibers (Figures $4 \mathrm{e}$ and $5 \mathrm{a}-\mathrm{c}$ ). However, $\beta 4$ signal was less resistant than $\mathrm{HaCaT}$ keratinocytes to detergent extraction ( $\sim 20 \%$; Figure $4 \mathrm{e}$ ). Most of the phosphorylation signal in the SCC cells was not resistant to detergent (Figure 4e). These findings are consistent with the notion that $\beta 4$ phosphorylation weakens HD stability.

Previous studies suggest that phosphorylated $\mathrm{S}_{1356} \mathrm{~S}_{1360} \mathrm{~S}_{1364}$ promotes disruption of $\beta 4$-plectin interactions. ${ }^{11}$ We therefore assessed phospho- $S_{1356} /$ plectin and plectin/total $\beta 4$ colocalization 

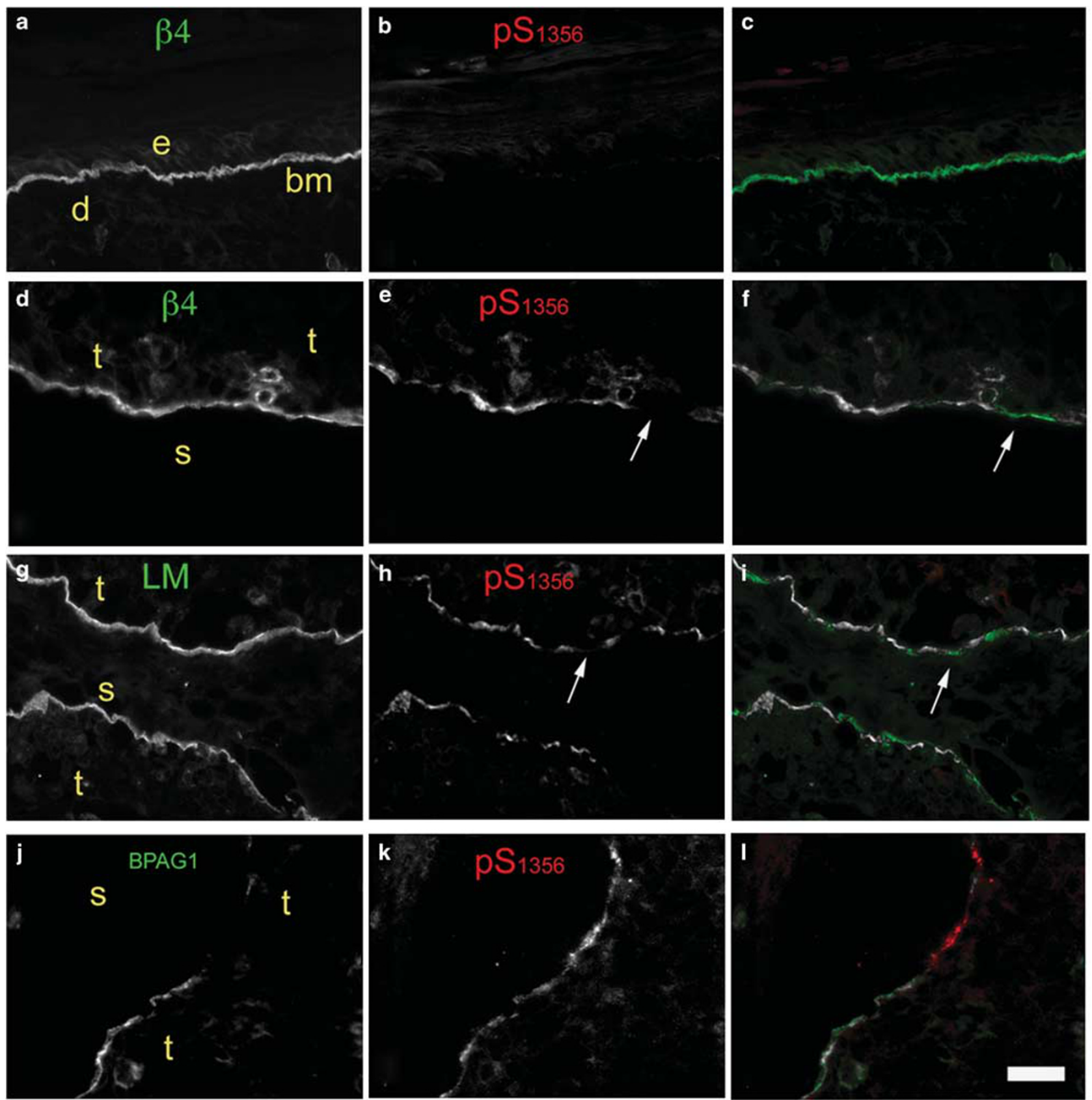

Figure 3 Distribution pattern of $\beta 4$ phosphorylation in human SCC frozen sections: discontinuous patches that can exclude other HD components. Frozen sections from skin $(\mathbf{a}-\mathbf{c})$ or invasive SCC $(\mathbf{d}-\mathbf{I})$ were dual-immunostained using Abs against (indicated within image): phospho- $\mathrm{S}_{1356}$ (red); and $\beta 4$, Laminin-332 or BPAG1 (green). Colocalization in the third column was determined by threshold correlation analysis, ${ }^{21}$ which shows correlating areas above threshold in white (colocalizing) or below threshold in red or green (non-colocalizing). e, epidermis; $d$, dermis; bm, basement membrane; $\mathrm{t}$, tumor; $\mathrm{s}$, stroma. Bar $=100 \mu \mathrm{m}$. Notice that $\beta 4$ phosphorylation may range from mildly discontinuous (e) to highly discontinuous (h). Laminin-332 is mostly continuous and does not follow phospho-S $\mathrm{S}_{1356}$ gaps $(\mathbf{g}-\mathbf{i})$. While both BPAG1 and phospho- $\mathrm{S}_{1356}$ phosphorylation are discontinuous they show segregation more frequently $(\mathbf{j}-\mathbf{I})$.

in SCC cells. A similar pattern was found for all SCC types (exemplified by SCC-25 in Figure 5), showing that while plectin usually colocalized with total $\beta 4$ in stabilized HD-like structures as previously described ${ }^{29}$ (Figures $5 \mathrm{~d}-\mathrm{f}$ ), phospho$\mathrm{S}_{1356}$ only partially overlapped with plectin and interestingly, within colocalized areas, an inverse gradient between the two signals was frequently observed (Figures $5 \mathrm{~g}-\mathrm{i}$ ), suggesting that plectin may be gradually removed as more $\beta 4$ becomes phosphorylated. We also assessed colocalization of phospho- $S_{1356}$ or total $\beta 4$ with BPAG1, another linker of $\beta 4$ with cytokeratins. While BPAG1 always colocalized with parts of the total $\beta 4$ (Figures $5 j-1$ ), a sharper segregation was seen 
a

C

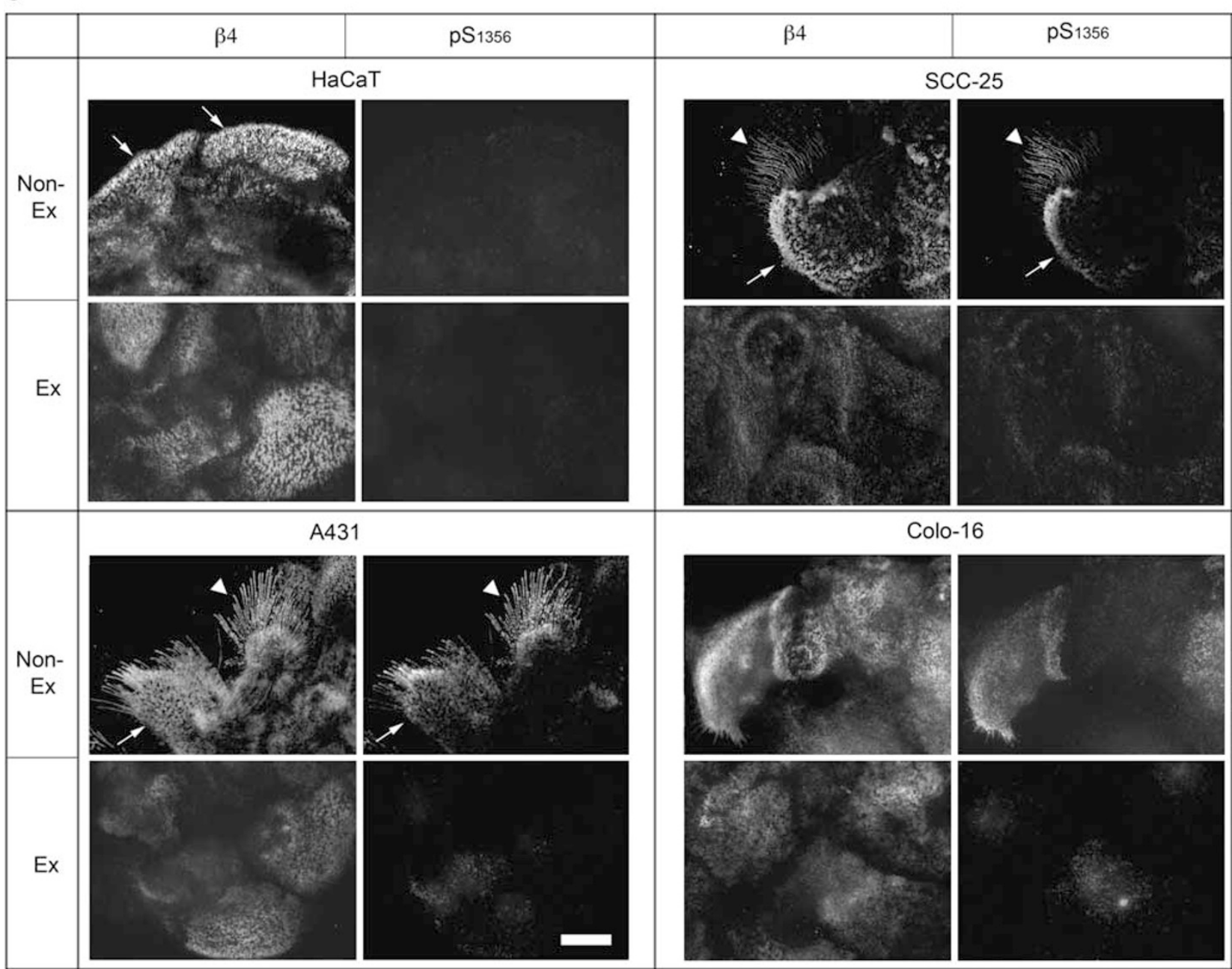

Figure 4 Increased basal levels of $\beta 4$ phosphorylation on $S_{1356}$ in SCC cells correlates with a reduction of HD-like structures. (a) Cell lysates from serum-starved $\mathrm{HaCaT}$ keratinocytes or SCC cells (A431, SCC-25, Colo-16) were analyzed by western blotting using phospho- $\mathrm{S}_{1356}$ and $\beta 4$ Abs. (b) Bands were quantified by densitometry. (c) IF analysis of total $\beta 4$ and phospho- $\mathrm{S}_{1356}$ spatial distribution in HaCaT keratinocytes and SCC cells. Cells grown on coverslips were serum-starved and detergent-extracted to identify HD-associated $\beta 4$ ('extracted'), or not to assess total $\beta 4$ ('non-extracted'), then fixed and stained using phospho- $\mathrm{S}_{1356}$ and $\beta 4 \mathrm{Abs}$. HaCaT keratinocytes show characteristic HD-like structures identified by $\beta 4$ staining on the basal aspect of the cell (thin arrows). Phospho-S 1356 signal can be observed in SCC cells (A431, SCC-25, and Colo-16) in HD-like structures (thin arrows) and retraction fibers (arrowheads). Bar $=10 \mu \mathrm{m}$. (d) Dual immunostaining analysis of detergent-extracted or non-extracted HaCaT cells using anti- $\beta 4$ (green) and anti-plectin antibodies (red). After detergent extraction most of the detergent-resistant $\beta 4$ colocalizes with plectin in HD-like structures. Bar $=10 \mu \mathrm{m}$. (e) Percentage of detergent-resistant $\beta 4$ in HD-like structures: Using IF analysis, the integrated fluorescence density for $\beta 4$ was calculated for cells extracted or not with detergent buffer before fixation as described in Materials and methods, and expressed as percentage of detergent-resistant $\beta 4 /$ total $\beta 4$. Data shown are mean values \pm s.e. of $>200$ cells. ${ }^{\star} P<0.05$. 
d
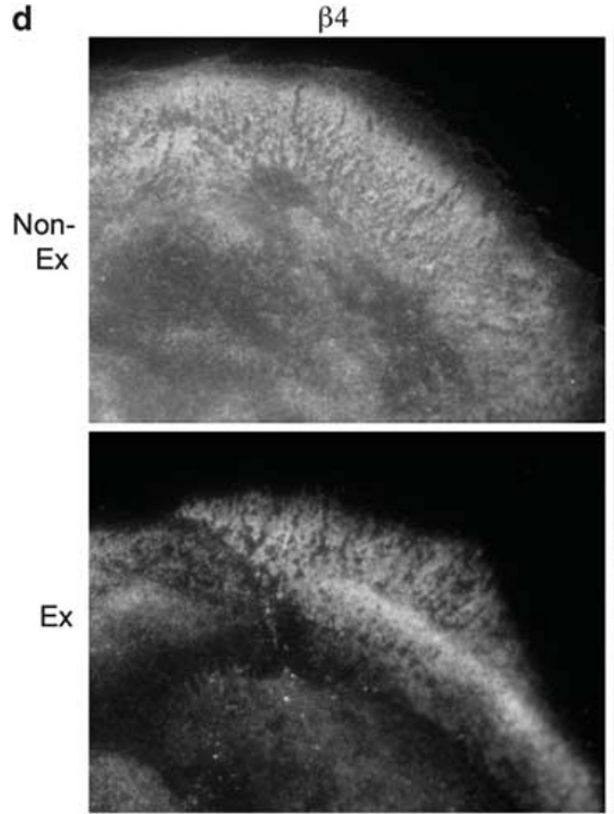

Plectin
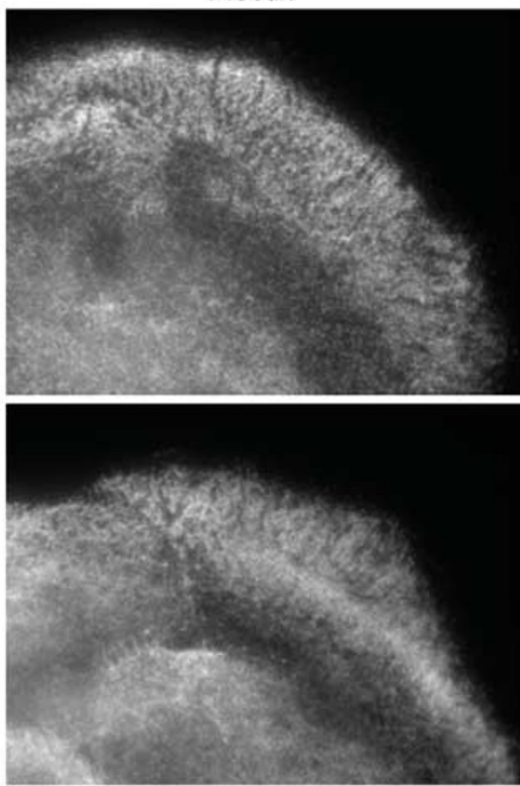

Colocalization
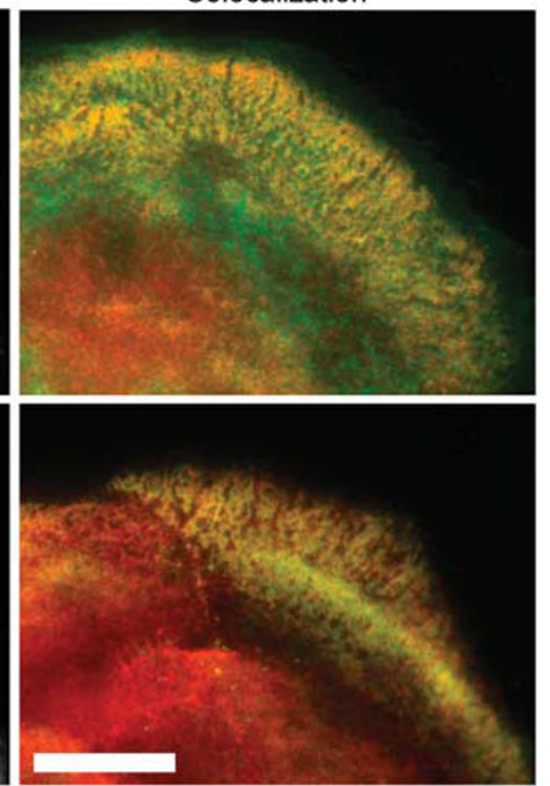

Figure 4 Continued.

between phospho- $\mathrm{S}_{1356}$ and BPAG1 (Figures $5 \mathrm{~m}-\mathrm{o}$ ), suggesting that other HD components are affected by phospho$\mathrm{S}_{1356}$ as well. Altogether these results suggest that SCC cells have intrinsic mechanisms to induce $\beta 4$ phosphorylation that might disrupt interactions among HD components, decreasing HD-like structure stability.

\section{Intrinsic Activation of EGFR Signaling Pathway in SCC Cells Raises Phospho- $S_{1356}$ Basal Levels Affecting HD-Like Structure Stability and Cell Migration}

To address the mechanisms that could generate an increase in the basal levels of $\beta 4$ phosphorylation in SCC, we determined whether this increase still depends on the EGF/PKC pathway. We evaluated phospho- $S_{1356}$ in the presence or absence of EGFR inhibitor Gefitinib or PKC inhibitor Go6976. As shown in Figure 6a, both Gefitinib and Go6976 inhibit phospho- $\mathrm{S}_{1356}$ basal levels in SCC cells, suggesting that activation of EGFR and PKC is still necessary in the absence of an external source of EGF and that SCC cells have intrinsic mechanisms to activate these kinases.

Since Gefitinib is used in some types of SCC chemotherapy, ${ }^{30}$ we addressed whether this drug could exert some of its anti-tumor effects through HD stabilization and modifying cell migration. As shown in Figure 6b, $\beta 4$ in HD-like structures is substantially increased using Gefitinib or Go6976. We then assessed their effect on SCC migration using in vitro wound healing assays. Both inhibitors efficiently reduced migration in all cells (Figure 6c). Go6976 effect was more pronounced, suggesting that alternative signaling pathways may converge with EGF signaling to activate PKC. These results suggest that anti-tumor activity of Gefitinib might include inhibition of SCC cell migration through HD stabilization and inhibition of $\beta 4$ phosphorylation.

\section{Prevention of $\beta 4$ Phosphorylation on $S_{1356} S_{1360} S_{1364}$ Restores HD-Like Structures in SCC Cells and Slows Migration}

Cell migration is an important component of carcinoma invasion and metastasis. ${ }^{31}$ Considering that SCC invasion correlates with $\beta 4$ phosphorylation and reduction of HD-like structures, we hypothesized that by preventing $\mathrm{S}_{1356} \mathrm{~S}_{1360} \mathrm{~S}_{1364}$ phosphorylation in SCC, we would replenish HD-like structures and hinder migration. Previous work in normal cells has shown that triple mutation is needed to increase HD stability. ${ }^{8,11}$ We therefore expressed in A431 a nonphosphorylatable triple mutant $\beta 4-\mathrm{A}_{1356} \mathrm{~A}_{1360} \mathrm{~A}_{1364}$-myc or a phosphorylation mimicking mutant $\beta 4-\mathrm{D}_{1356} \mathrm{D}_{1360} \mathrm{D}_{1364^{-}}$ myc, using wild-type (wt) $\beta 4$-myc as control. We first silenced $\beta 4$ endogenous expression in A431 using shRNA technology (targeting $\beta 4$ non-translated region). We then expressed wt and mutant $\beta 4$ at equivalent levels (Figure 7a). Using IF analysis and detergent extraction to assess HD-associated $\beta 4$, we found that $\beta 4$-myc and $\beta 4-\mathrm{A}_{1356} \mathrm{~A}_{1360} \mathrm{~A}_{1364^{-}}$ myc incorporated well into HD-like structures (Figure $7 \mathrm{~b}$, non-extracted $v s$ extracted). A quantitative analysis showed that $\beta 4-\mathrm{A}_{1356} \mathrm{~A}_{1360} \mathrm{~A}_{1364}$-myc produced twice the amount of HD-like structures as $\beta 4$-myc (Figure $7 \mathrm{c}$ ). In contrast, incorporation of $\beta 4-\mathrm{D}_{1356} \mathrm{D}_{1360} \mathrm{D}_{1364}$-myc into HD-like structures was reduced (Figures $7 \mathrm{~b}$ and $\mathrm{c}$ ). We addressed whether HD-like structure stabilization induced by $\beta 4-A_{1356} A_{1360} A_{1364}$-myc can counter EGF-induced HD disruption. As shown in Figure $7 c, \beta 4-\mathrm{A}_{1356} \mathrm{~A}_{1360} \mathrm{~A}_{1364}$-myc mutant efficiently resisted EGF-induced HD-like structure 


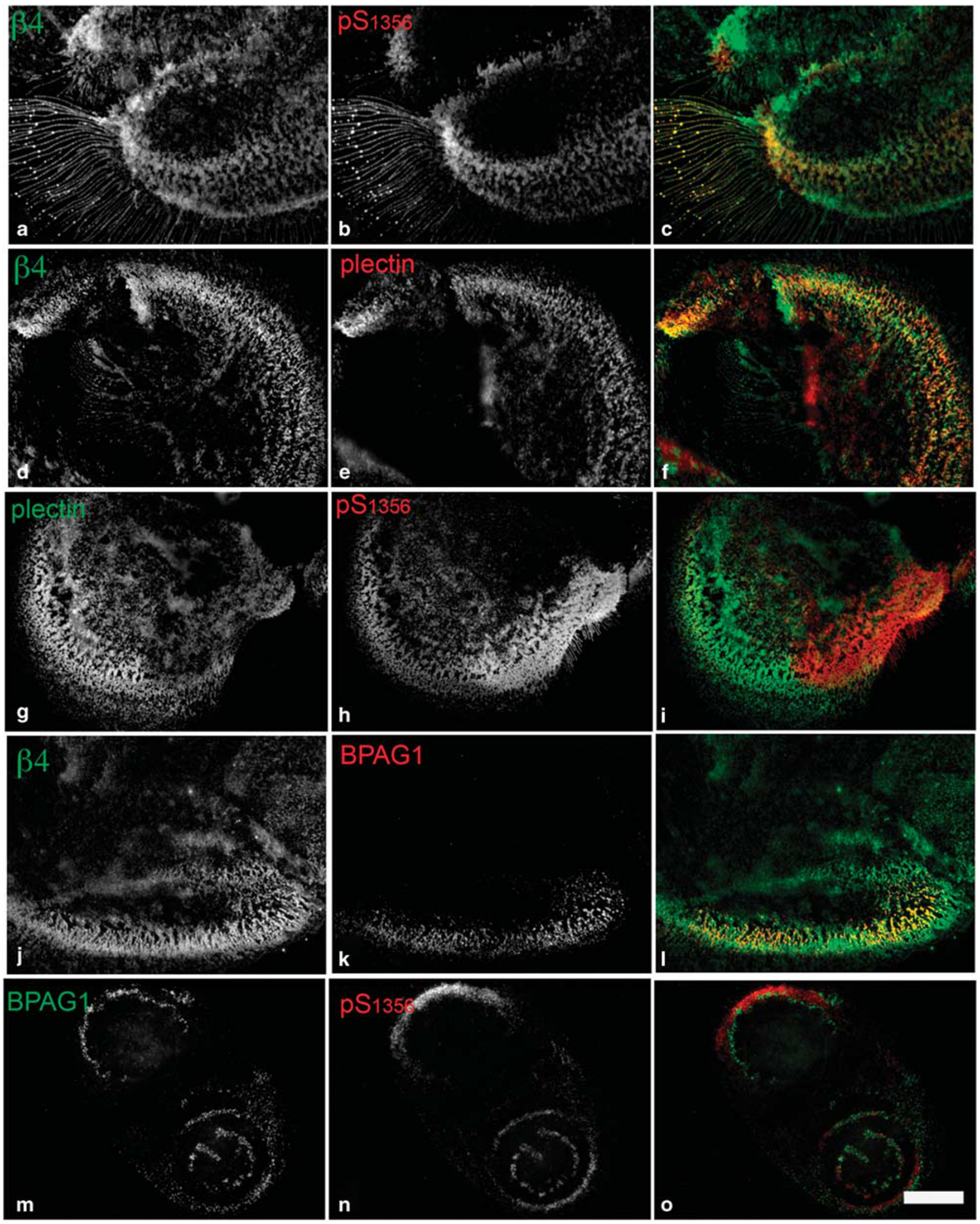

Figure 5 Phospho- $S_{1356}$ is partly segregated from other HD components in SCC cells. SCC- 25 cells were grown in coverslips, fixed, and stained for IF analysis using the indicated $\mathrm{Ab}$. The third column shows colocalization in yellow. $\beta 4$ and phospho- $\mathrm{S}_{1356}$ colocalize in retraction fibers and a portion of the HD-like structures (a-c). While HD component plectin colocalizes well with total $\beta 4$ in HD-like structures (d-f), it is partially segregated from the phospho- $\mathrm{S}_{1356}$ signal $(\mathbf{g}-\mathbf{i})$. Notice inverse gradients between phospho- $\mathrm{S}_{1356}$ and plectin signals in colocalized areas. HD component BPAG1 colocalizes well with $\beta 4(\mathbf{j}-\mathbf{I})$, whereas it is highly segregated from phospho- $\mathrm{S}_{1356}$ signal $(\mathbf{m}-\mathbf{0})$. Bar $=10 \mu \mathrm{m}$. 

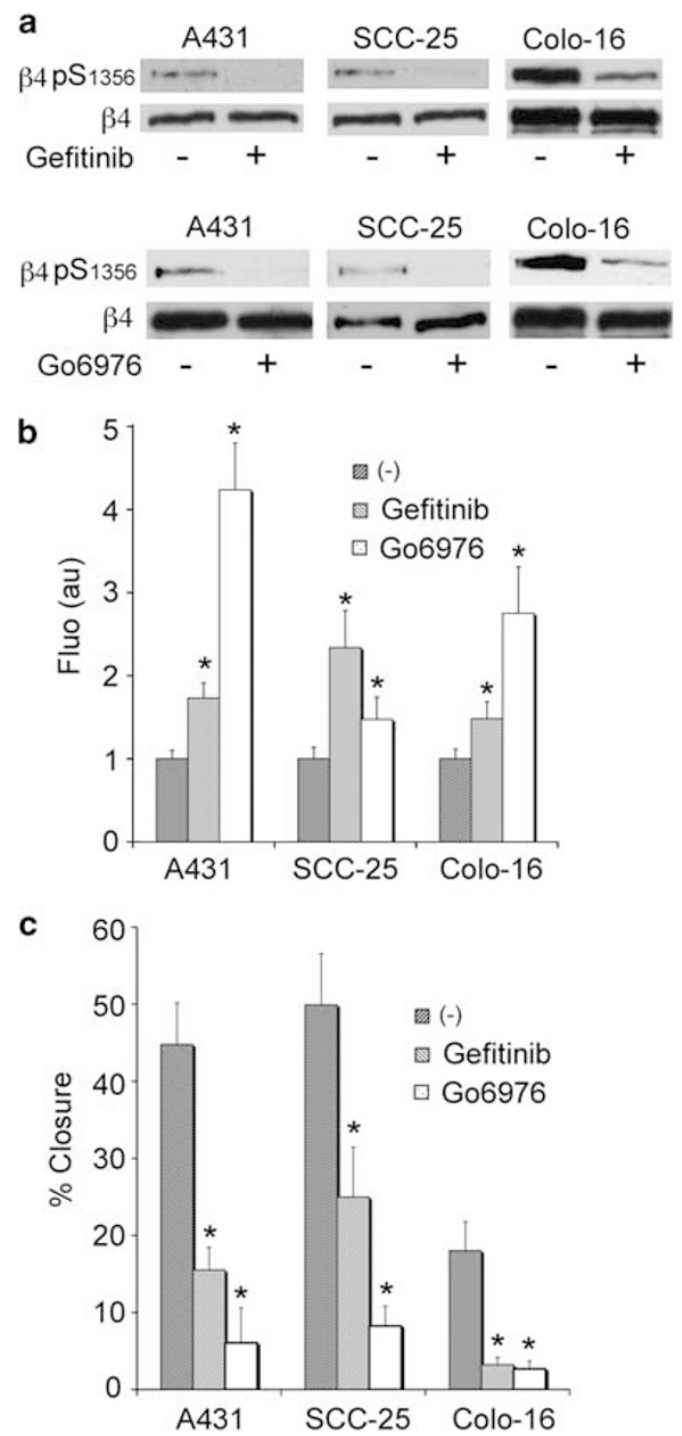

Figure 6 EGFR and PKC inhibitors reduce $S_{1356}$ basal phosphorylation in SCC cells, stabilizing HD-like structures and inhibiting cell migration. (a) Serum-starved SCC cells were treated or not with EGFR inhibitor Gefitinib (10 $\mu \mathrm{M}$, upper panel) or conventional PKC inhibitor Go6976 ( $2 \mu \mathrm{M}$, lower panel) for $1 \mathrm{~h}$, then lysed and analyzed by western blotting using phospho-S ${ }_{1356}$ and $\beta 4$ Abs. (b) Effects of Gefitinib and Go6976 on HD-like structures stability. SCC cells were grown on coverslips and treated or not with inhibitor for $1 \mathrm{~h}$, then detergent-extracted, fixed and processed for IF using anti- $\beta 4 \mathrm{Ab}$. The integrated fluorescence density for the HD-like structures was quantified as described in Materials and methods, and expressed in arbitrary units per cell. Data shown are mean values \pm s.e. of $>200$ cells. ${ }^{*} P<0.05$. (c) Effects of Gefitinib and Go6976 on SCC cell migration using in vitro wound healing assay. Confluent SCC cells were scratched with a yellow tip. Inhibitors were added or not, and the wound was allowed to close. Images captured at the start and end of the experiment were used to quantify wound closure (\%). Data shown are mean values \pm s.e. of three independent experiments ${ }^{*} P<0.05$.

disruption while $\beta 4$-myc was largely mobilized. These data suggest that low number of HD-like structures in SCC can be reverted by preventing $\beta 4$ phosphorylation.
We then assessed the ability of $\beta 4$ phosphorylation mutants to influence cell migration using wound healing assay. As shown in Figure $7 d, \beta 4-A_{1356} A_{1360} A_{1364}$-myc substantially reduced A431 migration. However, the phosphorylation mimicking mutant did not affect migration. These results suggest that regulation of $\beta 4$ phosphorylation can modulate cell movement through HD destabilization, although once $\beta 4$ leaves HDs, serine phosphorylation provides no further advantage.

\section{DISCUSSION}

HDs disassemble during wound healing and carcinoma invasion. In some types of SCC, the reduction of HDs is also associated with high metastatic potential. ${ }^{7}$ In this paper, we have explored the possibility that reduction of HDs in SCC is due to $\beta 4$ integrin serine phosphorylation. Consistent with this idea, we have found a correlation between an increase in $\beta 4$ integrin phosphorylation and carcinoma invasion in a group of 29 primary cutaneous SCC.

This is the first report showing that $\beta 4$ phosphorylation occurs in human tissue. The analysis of the $\beta 4$ phosphorylation in FFPE and frozen tissues showed a clear increase in phospho- $S_{1356}$ signal in $\sim 60 \%$ of the invasive SCC. However, we did not detect significant differences between the various degrees of differentiation among the invasive tumors. The phosphorylation signal was distributed unevenly, showing frequent gaps in the interface between the SCC and stroma, suggesting that the phosphorylation may be dependent on the context of the tumor location. Considering that EGFR activation is frequently seen in SCC and that $\beta 4$ can be phosphorylated through EGF signaling, one possible scenario to explain regional variations of $\beta 4$ phosphorylation would be a concomitant activation of EGFR within the same areas. We made efforts to detect phospho-EGFR and, although we found that SCC expressed EGFR, we were not able to detect phospho-EGFR (results not shown), a problem that has also been encountered by others studying cutaneous SCC. ${ }^{18}$ Interestingly, in other types of SCC, the existence of regional variations in phospho-EGFR has been reported, ${ }^{32}$ reminiscent of $\beta 4$ phosphorylation pattern. Another possibility is that regional phosphorylation of the $\beta 4$ integrin might reflect gaps in the basement membrane, a phenomenon that frequently occurs in invasive carcinoma. However, we found no relationship between the $\beta 4$ phosphorylation pattern and the basement membrane, which mostly showed a continuous distribution of Laminin-332, suggesting that $\beta 4$ phosphorylation is not determined by the basement membrane organization.

To gain more insight into what causes an increase in $\beta 4$ phosphorylation in SCC, we used an in vitro model of SCC. Our in vitro results suggest that SCC cells acquire intrinsic mechanisms to increase $\beta 4$ phosphorylation in the absence of any added growth factor. This increase of $\beta 4$ basal phosphorylation in SCC cells is accompanied by a reduction of HD-like structures and segregation of the phosphorylation 
a

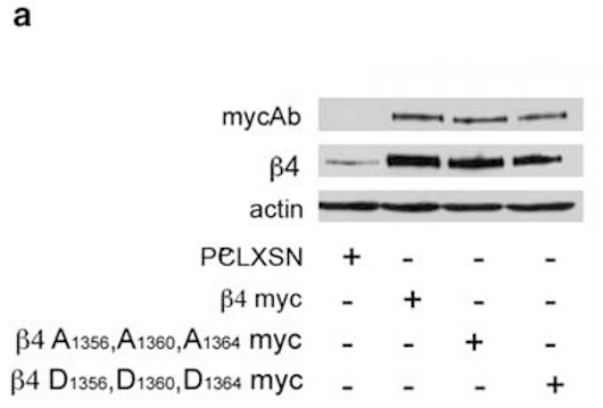

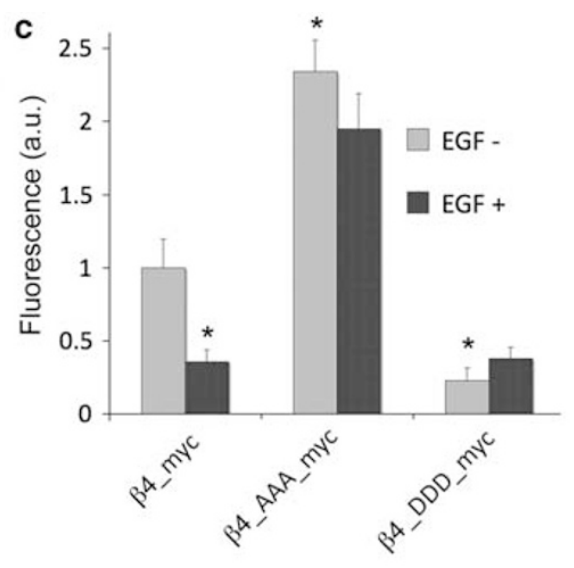

d

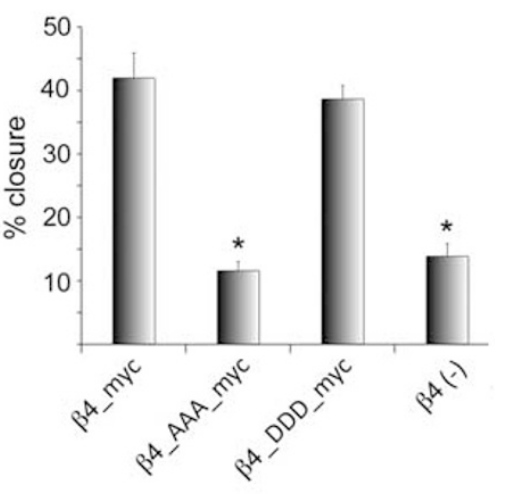

b

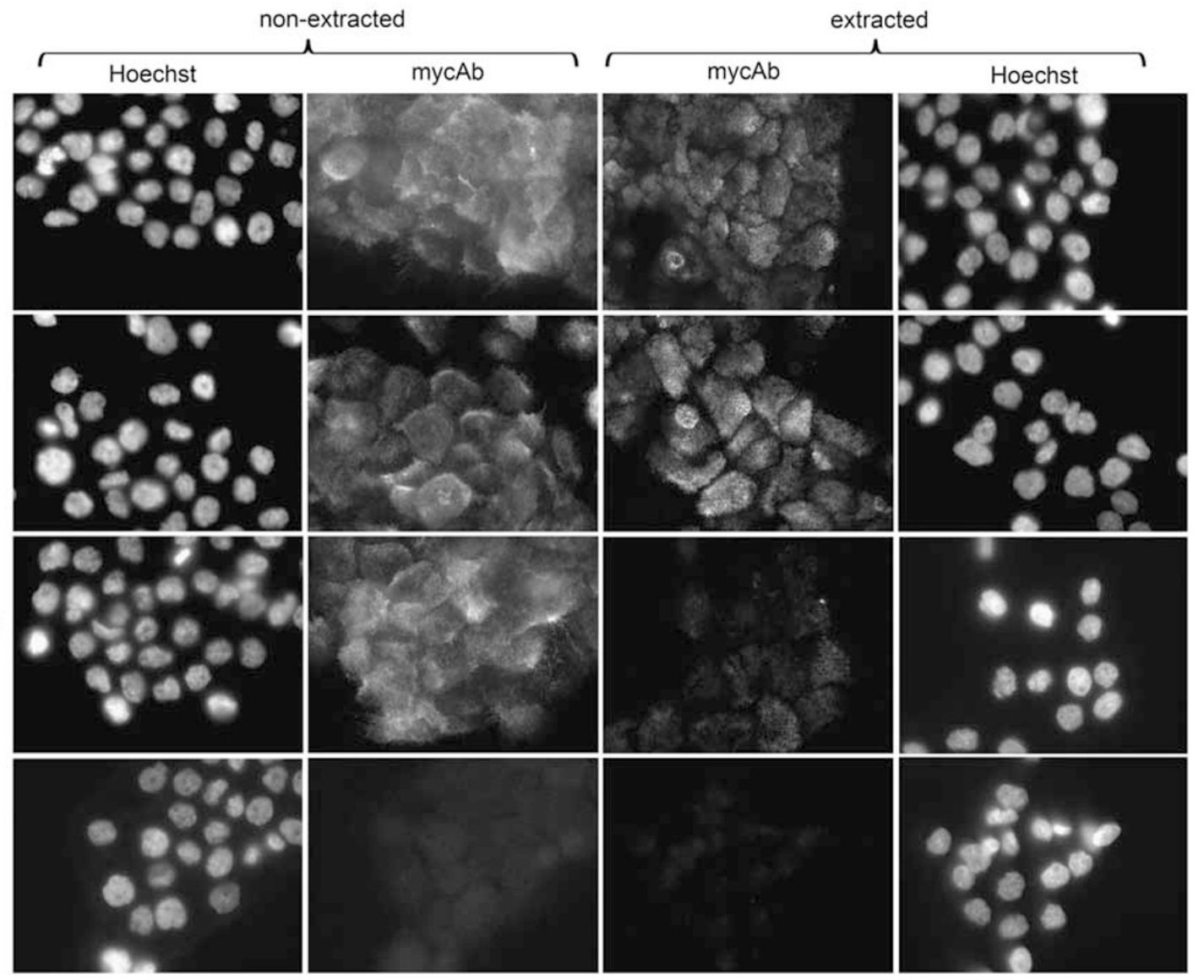

Figure 7 Abrogation of $\beta 4$ phosphorylation sites $\mathrm{S}_{1356} \mathrm{~S}_{1360} \mathrm{~S}_{1364}$ in SCC cells increases HD-like structure stability and hinders cell migration. Wild-type $\beta 4$-myc or triple mutants containing either a Ser $\rightarrow$ Ala ( $\beta 4$-AAA-myc) or $\mathrm{Ser} \rightarrow$ Asp ( $\beta 4$-DDD-myc) substitutions on $\mathrm{S}_{1356} \mathrm{~S}_{1360} \mathrm{~S}_{1364}$ were stably expressed in $\beta 4$ shRNA-silenced A431 cells. (a) Cells expressing the $\beta 4$ constructs were analyzed by western blotting using anti-myc Ab, showing similar level of expression. (b) Analysis of HD-like structures stability in $\beta 4$ phosphorylation mutants. Cells grown on coverslips were detergent-extracted or not before fixation, and processed for IF using anti-myc Ab. Notice that only wt $\beta 4$-myc and $\beta 4$-AAA-myc mutant were substantially retained in HD-like structures after extraction. (c) Resistance of $\beta 4$ phosphorylation mutants to EGF-induced HD-like structures disassembly. Cells on coverslips were treated or not with EGF for 30 min before being detergent-extracted, fixed and processed for IF using anti-myc Ab to analyze incorporation into HD-like structures. Quantitation of HD-like structures by digital image analysis is expressed in arbitrary units of fluorescence integrated density per cell. ${ }^{\star} P<0.05$. (d) Effect of $\beta 4$ mutants on cell migration using in vitro wound healing assay. Cells were assayed as in previous figure.

signal in relation to the HD components plectin and BPAG1, results that are consistent with the notion that $\beta 4$ phosphorylation promotes disassembly of HDs through the disruption of interactions with other HD components. ${ }^{8,11}$
Interestingly, we also observed segregation of BPAG1 and $\beta 4$ phosphorylation signal in SCC tissues, although the complete disappearance of BPAG1 within groups of cells in SCC suggests a different mechanism of segregation whereby 
continuous $\beta 4$ phosphorylation might eventually affect BPAG1 turnover or expression. Clearly, more studies are necessary to understand the long-term effects of $\beta 4$ phosphorylation on other HD components. One shared mechanism that the three SCC cell lines use to increase the basal phosphorylation of the $\beta 4$ integrin is the maintenance of an active EGFR in the absence of added growth factor, indicated by the inhibition of $\beta 4$ phosphorylation with Gefitinib, an EGFR kinase inhibitor. An active EGFR in such conditions would suggest the possibility of autocrine secretion of EGFR ligands or sensitizing mutation/amplification of EGFR. Constitutive activation of EGFR through expression of autocrine EGFR ligands, gain-of-function mutations, or protein overexpression is found in nearly $90 \%$ of all oral cavity and head and neck SCCs. ${ }^{2,30,33}$ In the specific case of A431, overexpression of EGFR and autocrine stimulation with TGF is well documented and may explain the increase in $\beta 4$ phosphorylation. ${ }^{34,35}$ Importantly, the inhibition of $\beta 4$ phosphorylation by Gefitinib correlated with stabilized HD-like structures and reduced cell migration in all SCC cells, suggesting that EGF effect on migration may be in part due to the regulation of $\beta 4$ phosphorylation promoting HD disassembly and allowing cells to move. Downstream EGFR, PKC still seems to mediate increased $\mathrm{S}_{1356}$ phosphorylation in SCC as shown by the inhibitory action of Go6976, a conventional PKC inhibitor. ${ }^{36}$ Therefore, SCC cells may only differ from keratinocytes in some type of disregulation of the EGF signaling pathway rather than the activation of an alternative route.

Our data suggest that $\beta 4$ phosphorylation might be involved in regulating the invasive ability of SCC through modulation of HD stability and cell migration. First, our results show that by inhibiting $\beta 4$ phosphorylation with Gefitinib in SCC cells, there was clear stabilization of HD-like structures, which correlated with cell migration inhibition. The effect on HD-like structure stability and cell migration was somewhat stronger using Go6976, suggesting that alternative signaling pathways may converge in the activation of PKC. Second, by preventing the phosphorylation of $\beta 4$ through mutation of the serine cluster $\mathrm{S}_{1356} \mathrm{~S}_{1360} \mathrm{~S}_{1364}$ to alanines, we were able to increase HD-like structure stability and inhibit migration even in the presence of EGF. However, a phosphorylation mimicking mutation of the serine cluster to aspartate failed to increase migration. This suggests that the role of $\beta 4$ integrin serine phosphorylation in SCC migration is to release the cell from migration-hindering attachment rather than actively promote migration. It is worth mentioning that $\beta 4$ per se was still necessary for cell migration, since silencing $\beta 4$ reduced migration, which is in agreement with previous studies, suggesting that $\beta 4$ itself promotes migration and invasion through a variety of signaling pathways. ${ }^{37,38}$ In this regard, a role of $\beta 4$ tyrosine phosphorylation in the migration-promoting function of $\beta 4$ has been previously shown. ${ }^{39-42}$

An interesting implication of our findings is that some of the anti-tumorigenic effects of EGFR inhibitors, such as
Gefitinib, might be exerted through the stabilization of HDs by inhibiting $\beta 4$ serine phosphorylation and consequently affecting the migration capability of the tumor, which ultimately impacts metastatic potential. Future studies that evaluate the restoration of HDs and reduction of $\beta 4$ phosphorylation during Gefitinib treatments could be potentially useful in assessing treatment efficiency and providing additional prognosis value.

\section{ACKNOWLEDGEMENTS}

This work was sponsored by National Institutes of Health Grant numbers CA120202 (IR) and CA118916 (SL). We thank Dr Arthur Mercurio and Dr Don Senger for their useful discussions.

\section{DISCLOSURE/CONFLICT OF INTEREST}

The authors declare no conflict of interest.

1. Alam M, Ratner D. Cutaneous squamous-cell carcinoma. N Engl J Med 2001;344:975-983.

2. Pai SI, Westra WH. Molecular pathology of head and neck cancer: implications for diagnosis, prognosis, and treatment. Annu Rev Pathol 2009;4:49-70.

3. Scully C, Bagan J. Oral squamous cell carcinoma overview. Oral Oncol 2009;45:301-308.

4. Green KJ, Jones JCR. Desmosomes and hemidesmosomes-structure and function of molecular components [review]. FASEB J 1996;10: 871-881.

5. Borradori L, Sonnenberg A. Hemidesmosomes: roles in adhesion, signaling and human diseases. Curr Opin Cell Biol 1996;8:647-656.

6. Gipson IK, Spurr-Michaud S, Tisdale A, et al. Redistribution of the hemidesmosome components alpha 6 beta 4 integrin and bullous pemphigoid antigens during epithelial wound healing. Exp Cell Res 1993;207:86-98.

7. Herold-Mende C, Kartenbeck J, Tomakidi P, et al. Metastatic growth of squamous cell carcinomas is correlated with upregulation and redistribution of hemidesmosomal components. Cell Tissue Res 2001;306:399-408.

8. Rabinovitz I, Tsomo L, Mercurio AM. Protein kinase C-alpha phosphorylation of specific serines in the connecting segment of the beta 4 integrin regulates the dynamics of type II hemidesmosomes. Mol Cell Biol 2004;24:4351-4360.

9. Germain EC, Santos TM, Rabinovitz I. Phosphorylation of a novel site on the beta\} 4 integrin at the trailing edge of migrating cells promotes hemidesmosome disassembly. Mol Biol Cell 2009;20:56-67.

10. Dans M, Gagnoux-Palacios L, Blaikie $P$, et al. Tyrosine phosphorylation of the beta 4 integrin cytoplasmic domain mediates Shc signaling to extracellular signal-regulated kinase and antagonizes formation of hemidesmosomes. J Biol Chem 2001;276:1494-1502.

11. Wilhelmsen K, Litjens SH, Kuikman I, et al. Serine phosphorylation of the integrin beta4 subunit is necessary for epidermal growth factor receptor induced hemidesmosome disruption. Mol Biol Cell 2007; 18:3512-3522.

12. Margadant C, Frijns $\mathrm{E}$, Wilhelmsen $\mathrm{K}$, et al. Regulation of hemidesmosome disassembly by growth factor receptors. Curr Opin Cell Biol 2008;20:589-596.

13. Litjens SH, de Pereda JM, Sonnenberg A. Current insights into the formation and breakdown of hemidesmosomes. Trends Cell Biol 2006;16:376-383.

14. Mainiero $F$, Pepe $A$, Yeon $M$, et al. The intracellular functions of alpha6beta4 integrin are regulated by EGF. J Cell Biol 1996;134: 241-253.

15. Rabinovitz I, Toker A, Mercurio AM. Protein kinase C-dependent mobilization of the alpha6beta4 integrin from hemidesmosomes and its association with actin-rich cell protrusions drive the chemotactic migration of carcinoma cells. J Cell Biol 1999;146:1147-1160.

16. Santoro MM, Gaudino G, Marchisio PC. The MSP receptor regulates alpha6beta4 and alpha3beta1 integrins via 14-3-3 proteins in keratinocyte migration. Dev Cell 2003;5:257-271. 
17. Rowinsky EK. The erbB family: targets for therapeutic development against cancer and therapeutic strategies using monoclonal antibodies and tyrosine kinase inhibitors. Annu Rev Med 2004;55:433-457.

18. Rittie L, Kansra S, Stoll SW, et al. Differential ErbB1 signaling in squamous cell versus basal cell carcinoma of the skin. Am J Pathol 2007;170:2089-2099.

19. Hieda Y, Nishizawa $Y$, Uematsu J, et al. Identification of a new hemidesmosomal protein, HD1: a major, high molecular mass component of isolated hemidesmosomes. J Cell Biol 1992;116: 1497-1506.

20. Rabinovitz I, Mercurio AM. The integrin alpha6beta4 functions in carcinoma cell migration on laminin-1 by mediating the formation and stabilization of actin-containing motility structures. J Cell Biol 1997;139:1873-1884.

21. Costes SV, Daelemans D, Cho EH, et al. Automatic and quantitative measurement of protein-protein colocalization in live cells. Biophys 2004;86:3993-4003.

22. De Luca M, Tamura RN, Kajiji S, et al. Polarized integrin mediates human keratinocyte adhesion to basal lamina. Proc Natl Acad Sci USA 1990;87:6888-6892.

23. Giard DJ, Aaronson SA, Todaro GJ, et al. In vitro cultivation of human tumors: establishment of cell lines derived from a series of solid tumors. J Natl Cancer Inst 1973;51:1417-1423.

24. Rheinwald JG, Beckett MA. Tumorigenic keratinocyte lines requiring anchorage and fibroblast support cultures from human squamous cell carcinomas. Cancer Res 1981;41:1657-1663.

25. Moore GE, Merrick SB, Woods LK, et al. A human squamous cell carcinoma cell line. Cancer Res 1975;35:2684-2688

26. Boukamp P, Petrussevska RT, Breitkreutz D, et al. Normal keratinization in a spontaneously immortalized aneuploid human keratinocyte cell line. J Cell Biol 1988;106:761-771.

27. Carter WG, Kaur P, Gil SG, et al. Distinct functions for integrins alpha 3 beta 1 in focal adhesions and alpha 6 beta 4/bullous pemphigoid antigen in a new stable anchoring contact (SAC) of keratinocytes: relation to hemidesmosomes. J Cell Biol 1990;111(6 Part 2):3141-3154

28. Nievers MG, Kuikman I, Geerts D, et al. Formation of hemidesmosomelike structures in the absence of ligand binding by the (alpha)6(beta)4 integrin requires binding of $\mathrm{HD} 1 /$ plectin to the cytoplasmic domain of the (beta)4 integrin subunit. J Cell Sci 2000;113 (Part 6):963-973.

29. Niessen $\mathrm{CM}$, Hulsman $\mathrm{EH}$, Oomen $\mathrm{LC}$, et al. A minimal region on the integrin beta4 subunit that is critical to its localization in hemidesmosomes regulates the distribution of HD1/plectin in COS-7 cells. J Cell Sci 1997;110(Part 15):1705-1716.

30. Hynes $\mathrm{NE}$, MacDonald $\mathrm{G}$. ErbB receptors and signaling pathways in cancer. Curr Opin Cell Biol 2009;21:177-184.

31. Stetler-Stevenson WG, Aznavoorian S, Liotta LA. Tumor cell interactions with the extracellular matrix during invasion and metastasis. Ann Rev Cell Biol 1993;9:541-573.

32. Miyawaki M, Hijiya N, Tsukamoto Y, et al. Enhanced phosphorylation of the epidermal growth factor receptor at the site of tyrosine 992 in esophageal carcinomas. APMIS 2008;116:1097-1106.

33. Kupferman ME, Myers JN. Molecular biology of oral cavity squamous cell carcinoma. Otolaryngol Clin North Am 2006;39:229-247.

34. Van de Vijver MJ, Kumar R, Mendelsohn J. Ligand-induced activation of A431 cell epidermal growth factor receptors occurs primarily by an autocrine pathway that acts upon receptors on the surface rather than intracellularly. J Biol Chem 1991;266:7503-7508.

35. Fan Z, Lu Y, Wu X, et al. Antibody-induced epidermal growth factor receptor dimerization mediates inhibition of autocrine proliferation of A431 squamous carcinoma cells. J Biol Chem 1994;269:27595-27602.

36. Qatsha KA, Rudolph C, Marme D, et al. Go 6976, a selective inhibitor of protein kinase $C$, is a potent antagonist of human immunodeficiency virus 1 induction from latent/low-level-producing reservoir cells in vitro. Proc Natl Acad Sci USA 1993;90:4674-4678.

37. Shaw LM, Rabinovitz I, Wang HH, et al. Activation of phosphoinositide $3-\mathrm{OH}$ kinase by the alpha 6beta4 integrin promotes carcinoma invasion. Cell 1997;91:949-960.

38. O'Connor KL, Shaw LM, Mercurio AM. Release of CAMP gating by the alpha6beta4 integrin stimulates lamellae formation and the chemotactic migration of invasive carcinoma cells. J Cell Biol 1998;143:1749-1760.

39. Shaw LM. Identification of insulin receptor substrate 1 (IRS-1) and IRS-2 as signaling intermediates in the alpha6beta4 integrin-dependent activation of phosphoinositide $3-\mathrm{OH}$ kinase and promotion of invasion. Mol Cell Biol 2001;21:5082-5093.

40. Mariotti A, Kedeshian PA, Dans $M$, et al. EGF-R signaling through Fyn kinase disrupts the function of integrin alpha6beta4 at hemidesmosomes: role in epithelial cell migration and carcinoma invasion. J Cell Biol 2001;155:447-458.

41. Bertotti A, Comoglio PM, Trusolino L. Beta4 integrin activates a Shp2Src signaling pathway that sustains HGF-induced anchorageindependent growth. J Cell Biol 2006;175:993-1003.

42. Yang X, Dutta U, Shaw LM. SHP2 mediates the localized activation of Fyn downstream of the alpha6beta4 integrin to promote carci. Mol Cell Biol 2010;30:5306-5317. 